\title{
Comments by the Royal College of Psychiatrists on the Oglesby Report*
}

This report provides a much needed examination of the present system of processing claims for attendance and mobility allowances. The major recommendations fall into two categories, one dealing with administrative delays and the other with medical involvement.

It would seem to be both simple and logical to reduce the number of sites to which claim forms are transmitted. Streamlining this process, combined with more effective use of modern office technology, seems likely to make the most significant positive impact on the present system.

The report clearly urges the 'demedicalization' of assessment procedures in spite of the fact that the disabilities are so clearly related to medical disorder. The opinion is that 'lay' is cheaper than 'medical', yet highly trained non-medical professionals in clinical practice may take far longer to reach an obvious conclusion, and therefore prove more costly than a medically trained professional. The exclusion of the special expertise of many examining medical officers, examining medical practitioners and delegated medical practitioners would seem particularly unfortunate; it seems likely that greater advantage would ensue from improving the expertise rather than excluding it. The considerable disadvantage of increased reliance on GP involvement seems contradictory. Particularly puzzling is the suggestion that the attendance allowance procedure should change from what is acknowledged to be a good way of adjudication and review to a less satisfactory one in order that 'justice must be seen to be done'. At the present time, the Attendance Allowance Board has an adjudication function and this must inevitably contribute towards the relative uniformity of decision making. If it were only to act in an advisory capacity its credibility would be diminished. It is premature to recommend that the Attendance Allowance Board not be involved in decision taking, in view of the great variety of the cases brought for decision and the complex medical and legal issues involved.

The College considers that reliance on the general practitioner as the main and virtually only medical expertise available in the whole procedure of adjudication may prove erroneous. It is likely to serve well for the straightforward cases, but there will be many exceptions where more specialized advice is required. It is also difficult to see how there will be uniformity and hence equity in decisions as between similar cases. The College considers that there is a good case for greater employment of medical staff who are trained and have the expertise appropriate to the disability of claimants, particularly in the area of the more difficult or unusual cases. As regards the Attendance Allowance Board, the College considers that the adjudication function be retained as well as the advisory. In addition, the College recommends that there should be experienced and senior medical officers serving on the Board.

The suggestion that there be a 'study with sound statistical design' to evaluate the effect of lay as opposed to medical awards is difficult to conceive if the medical model no longer exists. Before the present system is dismantled, and in the presence of such doubts, there would appear to be a need to introduce pilot areas first and carefully evaluate them along with those already in existence.

The suggestion that patients in hospital who accumulate unspent monies from the mobility allowance should have the allowance modified or discontinued seems logical, but unfair unless other recipients of allowances are to be subject to similar financial scrutiny. It is difficult to quarrel with the suggestion that money that cannot be used shall not be allowed to accumulate in this particular case, but as with other situations in which money accumulates, there is a need for a solution as to how such money can be used whilst the longterm care section of the hospital service remains so underfunded.

This report is timely and makes firm proposals on ways in which the present systems for processing attendance and mobility allowances may be made more efficient and speedy. Other issues, in particular the value of medical versus lay opinion, seem to have little relevance to the problem of delay. It would seem appropriate, therefore, to adopt the potentially advantageous administrative changes, and monitor closely for problems so that the system most sensitive to the claimant's needs might evolve.

- Approved by Council, March 1985.

\section{Collegiate Trainees' Committee, 1985}

Scotland-Inceptors: Stella Clark, Ian Medley, Peter Rice; Senior Trainees: Michele Hampson, Katherine Leighton, Colin Shapiro.

North East-Inceptor: Janine Scott; Senior Trainees: Suresh Joseph, Michael Lough.

North West-Inceptor: Jaya Gurisunkur; Senior Trainees: Ian Davidson, Eric Mendelson.

Midlands-Inceptor: Dinesh Bhugra; Senior Trainees: Mairead O'Leary, David Neilson.

Chiltern and Thames Valley-Inceptor: Koon Choong Au Yong; Senior Trainees: Elaine Arnold, Robert Poole.
East Anglia-Inceptor: Mostapha Morsy; Senior Trainees: Riadh Abed, Peter White.

Southern-Inceptor: Dorothy Oglethorpe: Senior Trainees: David Cottrell, Gillian Mezey.

South West-Inceptor: Susan Johnston; Senior Trainees: Chris Gillespie, Julie Parker.

Wales-Inceptors: John Lovett, Sarah Watkins; Senior Trainee: Liaqat Ali.

Northern Ireland-Inceptor: Stephen McAuley; Senior Trainees: Frederick Browne, Michael Doherty.

Southern Ireland-Cork: Geraldine O'Sullivan; Dublin: Mary Staines; Galway: Antoinette Coffey. 